\title{
Refractory Digestive System Carcinoma
}

National Cancer Institute

\section{Source}

National Cancer Institute. Refractory Digestive System Carcinoma. NCI Thesaurus. Code C151906.

A carcinoma hat arises from any part of the digestive system and is resistant to treatment. 